\title{
Study on Transmission Characteristics of Integrated Shaft Vibration Isolation System in Transverse Vibration
}

\author{
Wei $\mathrm{Xu}^{1,2, \mathrm{a}}$ and Zechao $\mathrm{Hu}^{1,2,{ }^{*} . \mathrm{b}}$ \\ ${ }^{1}$ Institution of Noise and Vibration, Naval University of Engineering, Wuhan, China. \\ ${ }^{2}$ National Key Laboratory on Ship Vibration and Noise, Wuhan, China. \\ axuwei216@126.com, *, bhuzechao68@outlook.com
}

Keywords: Integrated; displacement; auxiliary engines; vibration; submarine; shaft vibrating.

\begin{abstract}
In order to reduce the vibration transmission from the propeller to the hull, the integrated shaft vibrating isolating system is used to support the bearings, the propulsion devices and the auxiliary engines. To achieve the goals of vibration and noise reduction of the hull, the vibration energy is attenuated by changing the vibration transmission path of the coupling system. In this paper, the concept of the integrated shaft vibrating isolating system was put forward, the mechanical model of the shaft system was established. The dynamic characteristics of system's transverse vibration were analyzed by using analytic method and finite element method. Based on the displacement response at the bearing and force transmission rate, the vibration isolation effects of two different ways by traditional support and elastic support were compared and analyzed. The results show that the displacement response of the bearing under the whole elastic supported shaft system is smaller than the traditional support method. The integrated elastic support method reduces the vibration isolation effect by $10.9 \mathrm{~dB}$ within $15 \sim 100 \mathrm{~Hz}$, and the effect of low frequency vibration attenuating is very evident. The feasibility of the design of integrated shaft vibration isolation system is verified. Therefore, a new method is put forward to design the vibration and noise reduction of the coupling system in the stern of the submarine.
\end{abstract}

\section{Introduction}

The radiated noise of low frequency line spectrum generated by the ship power plant is the acoustic fingerprint of the ship, which is easily detected by the enemy sonar and affects the ship stealth performance. Therefore, it is very important to control the mechanical vibration of large ship power plant in the noise control technology related to ship stealth performance. The introduction of double resilient mounting system or floating raft vibration isolation system has been able to solve most of the vibration isolating problems of large-scale power plant in the ship. However, since the ship power equipment noise was well controlled, the low-frequency noise generated by the shaft system has become a new disadvantage. The vibration is mainly generated by the periodic pulse excitation force in the non-uniform flow field. The excitation frequency is composed of axial frequency, leaf frequency and its multiplier frequency, concentrated in the low frequency band between $10 \sim 100 \mathrm{~Hz}$.

There are mainly three ways to reduce radiated noise from propeller-shaft-hull coupling system. One is to improve at the noise source, which is to reduce the unsteady excitation force through the structural optimal design of the propeller. The other way is to start at the noise radiation, that is, to reduce underwater radiated noise by optimizing the hull structure of the ship. The third way is to change the vibration transmission path of the coupling system by the design of the vibration isolation system1. Considering the design of propeller and hull structure relies on the improvement of the overall industrial technology in our society, the third way is undoubtedly a simple and efficient measures to reduce the vibration and noise of the hull. Currently, the ship power plant is generally mounted flexibly on the housing base by a vibration isolation device, so that the mechanical vibration of the plant can be effectively attenuated2. However, most of the ship bearings are rigidly connected to the hull, the fluctuation incentive force generated by the propeller is directly transmitted to the hull 
through each bearing of the shaft system, thus driving the hull to vibrate and radiate noise into the water.

Compared with the traditional rigid support method, J. Y. He3 put forward the concept of thrust bearing integrated vibration isolation system (IVIS), which make the thrust bearing and the ship power plant mounted on a large public floating raft. He pointed out that the vibration isolation effect of the IVIS is better than the traditional method in the low frequency range and can make the coupling system's vibration effectively attenuated in longitudinal direction. The above vibration isolation method also puts forward the adaptive requirement for the thrust bearing: first, when the thrust bearing pedestal produces radial displacement, the bearing's load should be controlled within a reasonable range; then, when the thrust bearing deflection occurs, the oil film lubrication characteristics should meet the requirements. According to the above demands, Z. M. Li4 developed a self-alignment and floatable thrust bearing with the ability of displacement and misalignment compensation function, which solved the operating safety problems of thrust bearing under the vibration isolation system. However, as the journal bearings still followed the traditional rigid support method, transverse vibration has no isolation effect in the low frequency range5.

For the vibration control of the propeller-shaft coupling system, the difficulty is to overcome the contradiction between the demand of vibration isolation effect and the permissible displacement response6. In order to meet the shaft alignment, the dynamic response of the shaft system can't be too large for acquiring a good vibration isolation effect. In this paper, the concept of Integrated Shaft Vibration Isolation System (ISVIS) is put forward. Based on the literature 2, a large power plant, thrust bearing and journal bearings are integrated in a large public floating raft and the entire system is elastically supported by the air springs. In view of the fact that the floating raft isolation platform has the property of large impedance, under the requirements of shaft alignment, the vibration energy transmitted from propeller to the hull can be further attenuated by changing the transmission path of the fluctuation incentive force.

\section{The Scheme of Integrated Shaft Vibration Isolation System}

As shown in Fig.1, compared with traditional support scheme, all the bearings and the ship power plant are integrated in a large public floating raft, which is supported by the air springs. The fluctuation incentive force is transmitted through the bearings to the floating raft, and at the same time the concentrated force acting on the floating raft is converted into the dispersing force acting on the air springs. By adjusting the pressure in the airbag7, the air springs' deformation can be controlled within a reasonable range to prevent the shaft misalignment, which in turn controls the dispersion forces transmitted to the hull. The ISVIS has the advantages of large rigidity and low natural frequency, which can make sure that not only the vibration isolation system has a good isolation effect in the wide frequency range, but also the deformation of the shaft system can be reduced. Under the precondition that the requirements of the shafting alignment are satisfied, the vibration energy transmitted form propeller to the hull can still be effectively attenuated.

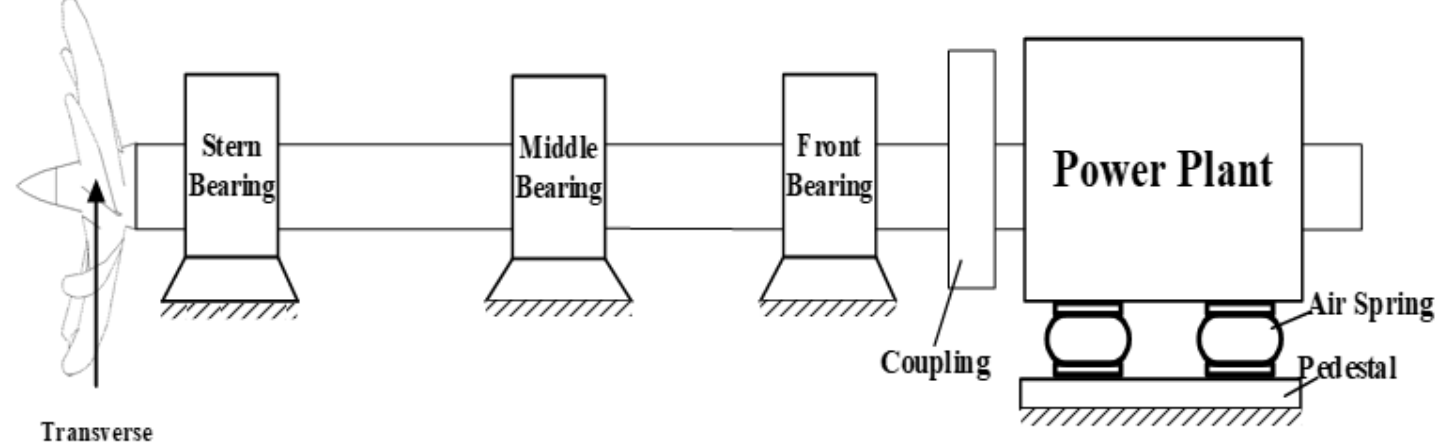

Excitation Force

(a)Traditional Support Method 




(b)ISVIS Method

Fig. 1. Support Method of Shaft System

\section{Transverse Vibration Model of ISVIS}

In order to study the vibration isolation effect of the traditional support method and the ISVIS, a simplified model was established as shown in Fig. 2. In this figure, the front bearing is a thrust bearing, the middle bearing and the stern bearing are journal bearings. Each bearing is simplified as a single-point elastic supported spring element. For the front bearing and the middle bearing, the fulcrum should be taken at a position corresponding to $1 / 2$ of the sleeve length. As for stern bearing, taken the cantilever effect of the propeller into consideration, the fulcrum should be taken at a position corresponding to $1 / 4$ of the sleeve length. Spring units are used to simulate the bearings' radial stiffness, and the stiffness from stern to bow are $\mathrm{K} 1, \mathrm{~K} 2$ and $\mathrm{K} 3$ respectively. The propeller and the elastic coupling can be reduced to mass element coupled with the shaft. Considering the influence of the moment of inertia caused by the shear deformation of the shaft on its flexural vibration, the shaft can be simplified as a modified Timoshenko beam element. The air spring can be simplified as a spring element with stiffness and damping in three directions. The elastic coupling has a certain displacement compensation capability, so it is usually simplified as a mass element and the end face of it can be regarded as a free end8.

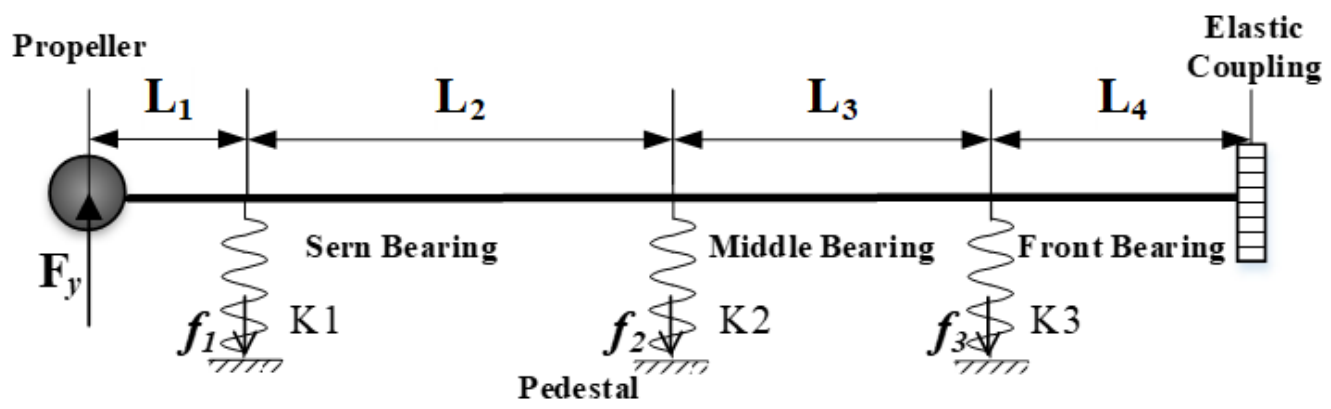

(a)Simplified Model of Traditional Support Scheme

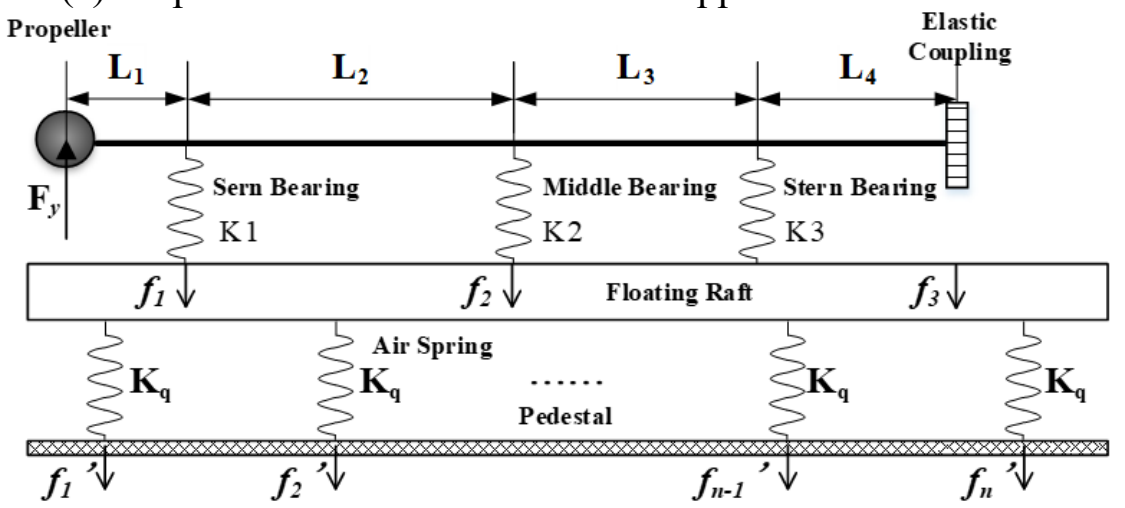

(b)Simplified Model of Shaft Isolating System

Fig. 2. Simplified Model 


\subsection{Modification of Motion Equation of Timoshenko Beam}

In order to reduce the accumulated error of Timoshenko beam theory caused by the neglect of secondary factors, Literature 9 considered the influence of rotational inertia caused by beam shear deformation on the basis of Timoshenko beam theory and deduced the modification of flexural motion equation of Timoshenko beam shown in Eq. (1).

$$
E I \frac{\partial^{4} y}{\partial x^{4}}+m \frac{\partial^{2} y}{\partial t^{2}}-m r^{2} \frac{\partial^{4} y}{\partial x^{2} \partial t^{2}}-\frac{E I}{k^{\prime} A G} m \frac{\partial^{4} y}{\partial x^{2} \partial t^{2}}=0
$$

In Eq. (1), E, G, I am the Young's modulus, the shear modulus, the cross-section moment of inertia, respectively. $y=y(x, t)$ is the deflection of the beam, $k^{\prime}$ is the cross-section shear coefficient, A is the effective shear area, $r$ is the cross-section radius of the beam. Eq. (2) is the general solution of Eq. (1).

$$
y(x, t)=u(x) \sin (\omega t+\gamma)
$$

In Eq. (2), $u(x)$ is the vibration mode function of the beam, $\omega$ is the excitation frequency, $\gamma$ is the initial phase. Eq. (3) can be derived by introducing Eq. (2) into Eq. (1).

$$
\frac{d^{4} u}{d x^{4}}+\frac{\delta+\tau}{l^{2}} \frac{d^{2} u}{d x^{2}}-\frac{\eta^{4}}{l^{4}} u=0
$$

In Eq. (3), $\tau=\frac{m \omega^{2} r^{2}}{E I} l^{2}, \delta=\frac{m \omega^{2}}{k^{\prime} A G} l^{2}, \eta^{4}=\frac{m \omega^{2}}{E I} l^{4}$. By substituting the solution of the fourth-order constant coefficient differential equation into the Eq. (3), the eigenvalue of the equation and the mode function $u(x)$ can be expressed as Eq. (4) and Eq. (5) respectively.

$$
\begin{aligned}
s_{1,2} & =\left\{\left[\eta^{4}+\frac{1}{4}(\delta+\tau)^{2}\right]^{\frac{1}{2}} \mp \frac{1}{2}(\delta+\tau)\right\}^{\frac{1}{2}} \\
u(x) & =\bar{c}_{1} e^{s_{1} x / l}+\bar{c}_{2} e^{-s_{1} x / l}+\bar{c}_{3} e^{i s_{2} x / l}+\bar{c}_{4} e^{-i s_{2} x / l}
\end{aligned}
$$

\subsection{Transverse Vibration Response Calculation of the Shaft System}

\subsubsection{Modified Timoshenko Beam Transfer Matrix}

By calculating the corresponding relation of deflection $u(x)$, angle $\theta(x)$, bending moment $M(x)$ and the shear force $Q(x)$ of beam element, the vector relationships between the two ends of the Modified Timoshenko beam element was deduced according to the literature 10. The beam flexural vibration transfer matrix $\mathbf{T}_{\mathbf{i}}$ can be expressed as equation (6).

$$
\mathbf{T}_{i}=\mathbf{B}\left(L_{i}\right) \cdot \mathbf{B}^{-1}(0)
$$

In Eq. (6), $L_{i}$ is the length of the shaft element of component $i, x \in\left[0, L_{i}\right], \mathbf{B}(0)=\left.\mathbf{B}(x)\right|_{x=0}$, $\mathbf{B}\left(L_{i}\right)=\left.\mathbf{B}(x)\right|_{x=L_{i}}$. The transmission matrix of a certain point in the length direction of the shaft element can be expressed as Eq. (7).

$$
\mathbf{B}(x)=\left[\begin{array}{cccc}
\frac{s_{1}}{m \omega^{2} L_{i}} \sinh \left(s_{1} X / L_{i}\right) & \frac{s_{1}}{m \omega^{2} L_{i}} \cosh \left(s_{1} X / L_{i}\right) & -\frac{s_{2}}{m \omega^{2} L_{i}} \sin \left(s_{2} X / L_{i}\right) & \frac{s_{2}}{m \omega^{2} L_{i}} \cos \left(s_{2} X / L_{i}\right) \\
\frac{s_{1}{ }^{2}+\delta}{m \omega^{2} L_{i}^{2}} \cosh \left(s_{1} X / L_{i}\right) & \frac{s_{1}{ }^{2}+\delta}{m \omega^{2} L_{i}^{2}} \sinh \left(s_{1} X / L_{i}\right) & -\frac{s_{2}{ }^{2}-\delta}{m \omega^{2} L_{i}^{2}} \cos \left(s_{2} X / L_{i}\right) & -\frac{s_{2}{ }^{2}-\delta}{m \omega^{2} L_{i}{ }^{2}} \sin \left(s_{2} X / L_{i}\right) \\
\frac{E s_{1}\left(s_{1}{ }^{2}+\delta\right)}{m \omega^{2} L_{i}^{3}} \sinh \left(s_{1} X / L_{i}\right) & \frac{E I s_{1}\left(s_{1}{ }^{2}+\delta\right)}{m \omega^{2} L_{i}^{3}} \cosh \left(s_{1} X / L_{i}\right) & \frac{E I s_{2}\left(s_{2}{ }^{2}-\delta\right)}{m \omega^{2} L_{i}{ }^{3}} \sin \left(s_{2} X / L_{i}\right) & -\frac{E I s_{2}\left(s_{2}{ }^{2}-\delta\right)}{m \omega^{2} L_{i}{ }^{3}} \cos \left(s_{2} X / L_{i}\right) \\
\cosh \left(s_{1} X / L_{i}\right) & \sinh \left(s_{1} X / L_{i}\right) & \cos \left(s_{2} X / L_{i}\right) & \sin \left(s_{2} X / L_{i}\right)
\end{array}\right]
$$

\subsubsection{The Transfer Matrix of the Mass and Spring Element}

When establishing the analytical model of the propeller-shaft system, the propeller and the elastic coupling are simplified to the lumped mass, and the bearings are simplified to the spring elements. 
The corresponding transverse transfer matrix is expressed as $\mathbf{P}_{P}, \mathbf{P}_{C}, \mathbf{P}_{K i}$ in Eq. (8) (10) respectively, where $\mathrm{i}=1,2,3$ are the bearing numbers as shown in Fig. $4, M_{P}, J_{P}, K_{i}$ are the mass of propeller, the moment of inertia of the propeller, the transverse stiffness of each bearing.

$$
\begin{aligned}
\mathbf{P}_{P} & =\left[\begin{array}{cccc}
1 & 0 & 0 & 0 \\
0 & 1 & 0 & 0 \\
0 & J_{P} \omega^{2} & 1 & 0 \\
M_{P} \omega^{2} & 0 & 0 & 1
\end{array}\right] \\
\mathbf{P}_{C} & =\left[\begin{array}{cccc}
1 & 0 & 0 & 0 \\
0 & 1 & 0 & 0 \\
0 & 0 & 1 & 0 \\
M_{C} \omega^{2} & 0 & 0 & 1
\end{array}\right] \\
\mathbf{P}_{K i} & =\left[\begin{array}{cccc}
1 & 0 & 0 & 0 \\
0 & 1 & 0 & 0 \\
0 & 0 & 1 & 0 \\
-K_{i} & 0 & 0 & 1
\end{array}\right]
\end{aligned}
$$

\subsubsection{Transverse Vibration Response of the Bearing Housing}

When the periodic pulse excitation force $f_{0}$ is acted on the propeller, the relationship between state vectors of the right and the left ends of the shaft system is presented in Eq. (11), where $T_{i j}$ represent the $\mathrm{i}$-th row and $\mathrm{j}$-th column element of the matrix $\mathbf{T}$. Vibrations along the shaft from the propeller to the coupling need to go through 9 units, $\left[\begin{array}{lllll}u & \theta & M & Q\end{array}\right]_{i}^{L}$ and $\left[\begin{array}{llll}u & \theta & M & Q\end{array}\right]_{i}^{R}$ represent the i-th element of left and right ends states vector. Substituting the free-free boundary conditions ( $M_{1}^{L}=Q_{1}^{L}=M_{9}^{R}=Q_{9}^{R}=0$ ) into Eq. (11), then the Eq. (12) (13) can be deduced. In Eq. (12) and Eq. (13), $F_{z}, K_{z}, u_{z}$ are the force transmitted to the bearing, transverse stiffness of the bearings, deflection at the corresponding shaft element, respectively.

$$
\begin{aligned}
& \mathbf{T}=\mathbf{P}_{C} \mathbf{T}_{4} \mathbf{P}_{K 3} \mathbf{T}_{3} \mathbf{P}_{K 2} \mathbf{T}_{2} \mathbf{P}_{K 1} \mathbf{T}_{1} \mathbf{P}_{P} \\
& \left\{\begin{array}{l}
u_{1}^{L}=\frac{T(3,4) T(4,2)-T(3,2) T(4,4)}{T(3,1) T(4,2)-T(3,2) T(4,1)} \\
\theta_{1}^{R}=\frac{T(3,4) T(4,1)-T(3,1) T(4,4)}{T(3,2) T(4,1)-T(3,1) T(4,2)}
\end{array}\right. \\
& F_{z}=K_{z} u_{z}
\end{aligned}
$$

\subsubsection{Transverse Vibration Response of the Pedestal}

The semi-analytical method is used to solve the vibration response of the pedestal. Considering the subsystem of the floating raft with $\mathrm{m}$ inputs and $\mathrm{n}$ outputs, the input excitation force, displacement response are described as $\mathbf{f}_{\mathbf{I}}=\left\{\begin{array}{llll}f_{I 1} & f_{I 2} & \cdots & f_{I m}\end{array}\right\}^{T}, \mathbf{u}_{\mathbf{I}}=\left\{\begin{array}{llll}u_{I 1} & u_{I 2} & \cdots & u_{I m}\end{array}\right\}^{T}$ respectively, and the output force, displacement response are described as $\mathbf{f}_{\mathbf{o}}=\left\{\begin{array}{llll}f_{O 1} & f_{O 2} & \cdots & f_{O n}\end{array}\right\}^{T}$, $\mathbf{u}_{\mathbf{o}}=\left\{\begin{array}{llll}u_{O 1} & u_{O 2} & \cdots & u_{O n}\end{array}\right\}^{T}$ respectively. Taking the p input end $I_{p}$ and the q output end $O_{q}$ subsystem for an example, the four-end parameters' matrix of the floating raft can be described in Eq. (14).

$$
\left\{\begin{array}{c}
f_{I p} \\
u_{I p}
\end{array}\right\}=\left[\begin{array}{ll}
a_{11} & a_{12} \\
a_{21} & a_{22}
\end{array}\right]\left\{\begin{array}{c}
f_{O q} \\
u_{O q}
\end{array}\right\}
$$


Due to the strict limitation of the boundary conditions at the output end of subsystem when solving the impedance matrix element, the impedance matrix of the multi-input multi-output system is hard to measure. In contrast, the admittance matrix is easily obtained by measurement. In general, finite element analysis (FEA) or experimental method is used to obtain admittance elements of the subsystem. By acquiring the admittance matrix of the subsystem, the corresponding four-end parameters of the structure input and output end can be solved indirectly11.

\section{Discussions of Results}

It is assumed that the model parameters of the integrated shaft vibration isolation system are as shown Fig. 1, where $M_{P}=4000 \mathrm{~kg}$ is the propeller lumped mass, $M_{C}=800 \mathrm{~kg}$ is the elastic coupling lumped mass, $M_{t h}=500 \mathrm{~kg}$ is the thrust collar mass, $\mathrm{L} 1=1.2 \mathrm{~m}, \mathrm{~L} 2=3.8 \mathrm{~m}, \mathrm{~L} 3=2.3 \mathrm{~m}, \mathrm{~L} 4=1.7 \mathrm{~m}$ are the length of the shaft elements, $D=0.24 \mathrm{~m}, d=0.13 \mathrm{~m}$ are the outer diameter, inner diameter of the shaft, $\mathrm{E}=2.1 \times 10^{11} \mathrm{~Pa}, \rho=7850 \mathrm{~kg} / \mathrm{m}^{3}$ are the elastic modulus, density of the shaft and the floating raft, $\mathrm{K} 1=7.8 \times 10^{8} \mathrm{~N} / \mathrm{m}, \mathrm{K} 2=6.0 \times 10^{8} \mathrm{~N} / \mathrm{m}, \mathrm{K} 3=3.5 \times 10^{9} \mathrm{~N} / \mathrm{m}$ are the dynamic stiffness of each bearing in transverse direction. The thrust bearing oil film stiffness $K_{0}$ and damping $C_{0}$ are related to the rotating speed $n$ of the shaft and the exciting force $F$ on the propeller. When the rated rotating speed $n$ is $120 \mathrm{r} / \mathrm{min}$ and the propeller thrust $F$ is $100 \mathrm{kN}$, the corresponding $K_{0}$ is $1.4 \times 10^{10} \mathrm{~N} / \mathrm{m}$ and $C_{0}$ is $6.5 \times 10^{8} \mathrm{~N} \cdot \mathrm{m} / \mathrm{s}$.

In the simulation model, the rigidity of the elastic coupling is $1.36 \times 10^{7} \mathrm{~N} / \mathrm{m}$ in the axial direction and $8.4 \times 10^{6} \mathrm{~N} / \mathrm{m}$ in the transverse direction respectively. The mass of the power plant is $8.5 \mathrm{t}$, and the mass of the floating raft is $10.7 \mathrm{t}$. The floating raft is elastic supported by $16 \mathrm{JYQN}-2500$ air springs. The natural frequency of each air spring is $5.0 \mathrm{~Hz}$ and the rated load is $2.5 \mathrm{t}$. The transverse stiffness of the air spring is twice the vertical stiffness, and the damping ratio is 0.05 . The stiffness $K_{C}$ of the air spring changes linearly with the load $M$, so the formula for the parameters of the air spring is given by Eq. (15).

$$
\left\{\begin{array}{l}
K_{C}=4 \pi^{2} M f^{2} \\
C=\xi K_{C} / \pi f
\end{array}\right.
$$

The Finite Element Model (FEM) of the ISVIS is constructed as shown in Fig.3. As with the analytical model, in the FEM, the propeller and the elastic coupling are reduced to the lumped mass elements, and the shaft is simplified to the Timoshenko beam elements. The journal bearing is simplified to the spring elements with horizontal and vertical stiffness, and the thrust bearing with three-directional stiffness. The elastic coupling and the output end of the power plant flange are restrained by a spring. The upper pad of the air spring is connected with the floating raft, the lower pad is connected with the pedestal, and the pedestal is fixed. In order to avoid stress concentration, the area of the shell element that fixes the upper end of the spring and the raft frame is approximately the actual contact area. The confinement area between the air spring and the floating raft should be approximately equal to the actual contact area.

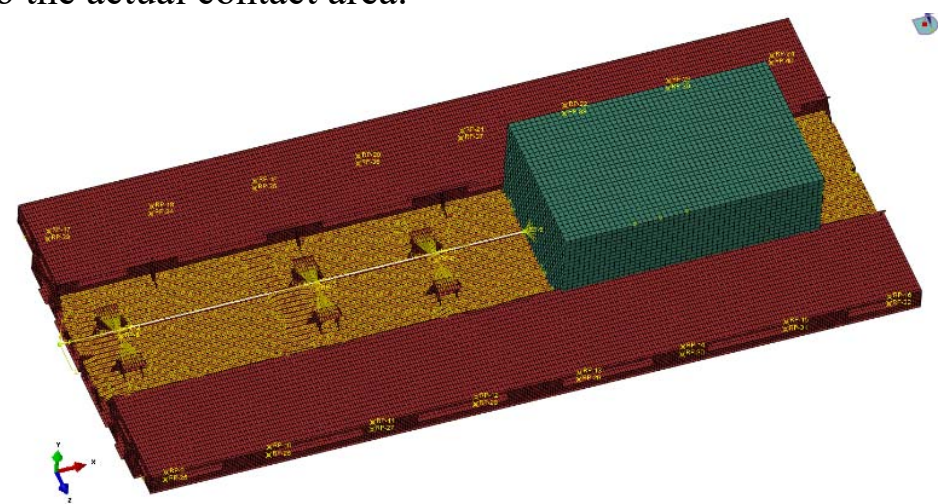

Fig. 3. FEM of Shaft Isolating System 
In the frequency range of $10 \sim 100 \mathrm{~Hz}$, the vertical harmonic excitation force with amplitude of $1 \mathrm{~N}$ is applied at the propeller. The displacement responses and the force transmissibility of the shaft system under different support conditions are calculated by using analytical method and FEA method respectively. The reference value of the vibration displacement level is $1 \mathrm{pm}$. The formula for calculating the force transmissibility of the ISVIS is shown in Eq. (16), where $F_{i}$ is the vertical elastic support force of the $\mathrm{i}$-th air spring and $F_{P}$ is the vertical excitation force of the propeller.

$$
T=20 \lg \left(\sum_{i=1}^{16} F_{i} / F_{p}\right)
$$

From Fig. 4 to Fig. 6, it can be seen that both the analysis method and FEA method results show the relevant frequencies of the shaft system modes, and the bearing displacement response vary with the frequency in the same trend. Due to the damping effect of the air springs and the high impedance characteristics of the large public floating raft, the displacement response of the bearing under the whole elastic supported shaft system is smaller than the traditional support method. It is shown that the vibration of the shaft system has not been amplified after changing the transmission path from the propeller to the hull. As shown in Fig. 7, because the ISVIS makes the transverse vibration transmission path more complicated, the peak of the force transmissibility curve increases obviously, but the amplitude of the single line spectrum is attenuated effectively. Above $15 \mathrm{~Hz}$, the vibration isolation effect of the ISVIS is obviously better than the traditional method. Compared with the traditional method, the total vibration isolation effect of the ISVIS is reduced by $10.9 \mathrm{~dB}$ in the low frequency range of $15 \sim 100 \mathrm{~Hz}$.

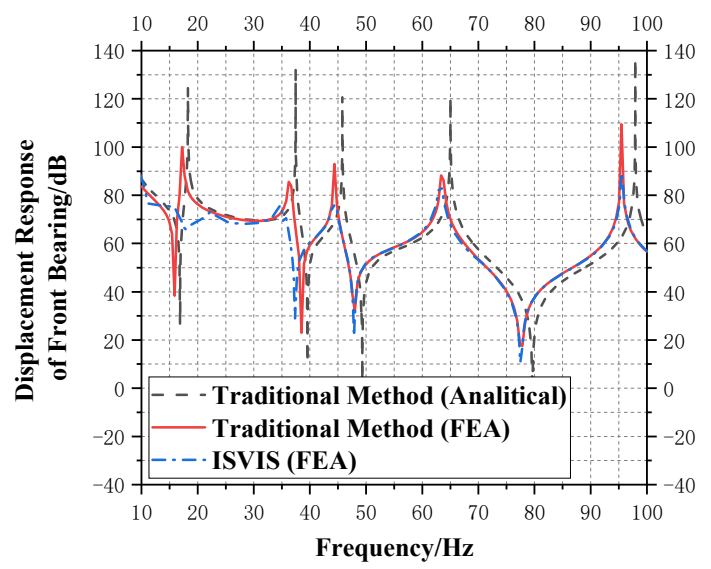

Fig. 4. Displacement response of stern bearing

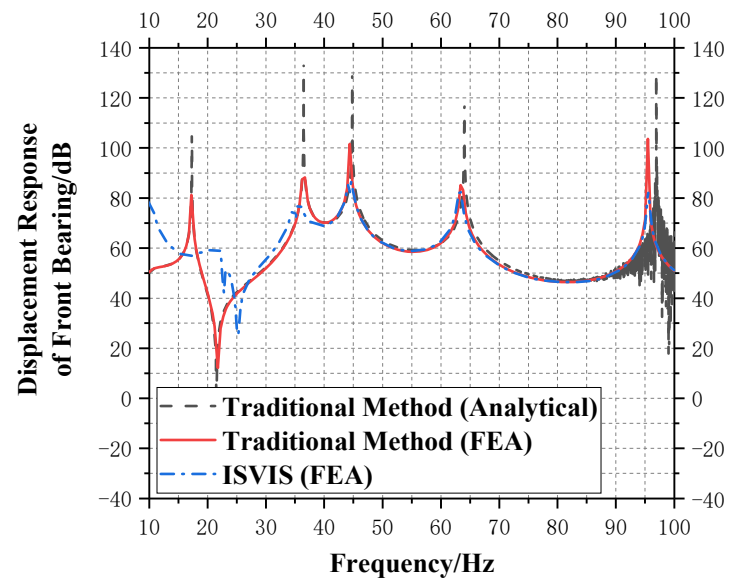

Fig. 6. Displacement response of front bearing

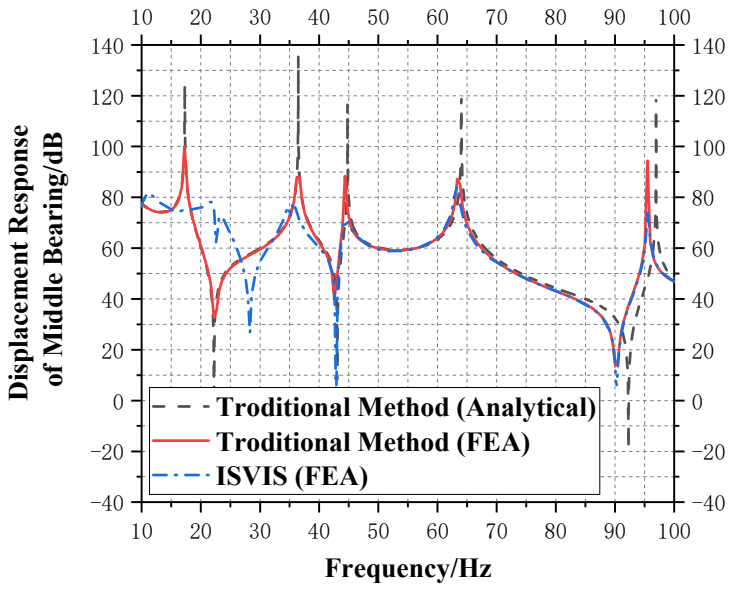

Fig. 5. Displacement response of middle bearing

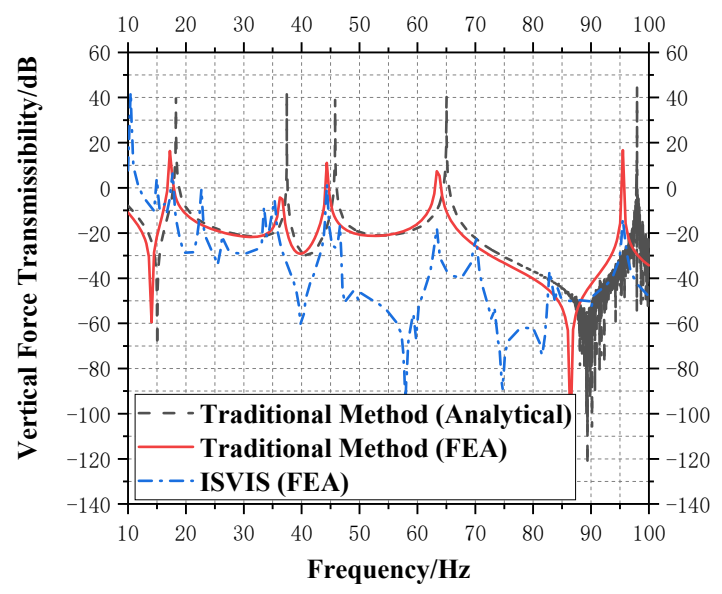

Fig. 7. Vertical force transmissibility 


\section{Conclusion}

In this paper, the concept of the ISVIS was put forward. The analytical method and the finite element method were used to establish the mechanical model of the shaft system. By analyzing the displacement response characteristics and the vibration isolation effect of the traditional support method and the ISVIS respectively, the feasibility of the design idea of the ISVIS is verified. The results show that the vibration of the shaft system has not been amplified after changing the transmission path from the propeller to the hull, considering the high impedance characteristics of the large public floating raft and the damping effect of the air springs. In the low frequency range, the vibration isolation effect of the ISVIS is obviously better than the traditional method. By changing the vibration transmission path from the propeller to the hull, the periodic pulse excitation force generated by the propeller is effectively attenuated. The design of the ISVIS can overcome the contradiction between the demand of the system's vibration isolation effects and the permissible displacement response. The ISVIS can provide a new method for the design of vibration and noise reduction in the stern of the submarine.

\section{References}

[1]. P. G. Dylejko, N. J. Kessissoglou. Minimization of the vibration transmission through the propeller-shafting system in a submarine (Journal of the Acoustical Society of America, New York, USA 2004), Vol. 116, Issues 4, pp. 65-69.

[2]. L. He, W. Xu, W. J. Bu, et al. Dynamic analysis and design of air spring mounting system for marine propulsion system (Journal of Sound and Vibration, London, England, 2014), Vol. 333, Issues 20, pp. 4912-4929.

[3]. J. Y. He, L. He, W. Xu. Research on damping capability of a new type of integrated vibration isolation system for longitudinal vibration of marine thrust bearing (Noise and Vibration Control, Shanghai, China 2017), Vol. 37, Issues 4, pp. 105-109.

[4]. Z. M. Li, L. He, W. Xu, et al. Compensation characteristics of leveling plates equalizing thrust bearing under shaft misalignment condition (Journal of Naval University of Engineering, Wuhan, China, 2016), Vol. 28, Issues 4, pp. 69-74.

[5]. J. Y. He. "Theoretical and experimental study of the integrated vibration isolation technology of submarine thrust bearing," Ph.D. thesis, Naval University of Engineering, 2017.

[6]. Lin $\mathrm{He}, \mathrm{W} . \mathrm{Xu}, \mathrm{W} . \mathrm{J} . \mathrm{Bu}$, et al. Development and application of new-type mounting system for naval vessel propulsion system (Journal of Ship Mechanics, Wuxi, China, 2013), Issues 11, pp. 1328-1338.

[7]. L. He, Y. L. Zhao. Theory and design of high-pressure and heavy-duty air spring for naval vessels (Journal of Vibration Engineering, Nanjing, China, 2013), Vol. 26, Issues 6, pp. 886-894.

[8]. G. B. Zhang, Y. Zhao, T. Y. Li, et al. Propeller excitation of longitudinal vibration characteristics of marine propulsion shafting system (Shock and Vibration, USA, 2014), Vol. 1, pp. 1-19.

[9]. R. Chen, C. F. Wan, X. T. Weng, et al. Modification of motion equation of Timoshenko beam and its effect (Journal of Tongji University, Shanghai, China, 2005), Vol. 33, Issues 6, pp. 711-715.

[10]. L. C. Wang. "Research of vibration and acoustic trait of submarine's propeller-shafting-hull interaction," Ph.D. thesis, Naval University of Engineering, 2013.

[11]. F. Zhang, S. H. Hao, M. S. Yu, et al. Evaluation and experimental research on floating raft isolation system by vectorial four pole parameter model (Journal of Ship Mechanics, Wuxi, China, 2011), Vol. 15, Issues 10, pp. 1173-1181. 